\title{
Difficulties in the Management and Prognosis of Cervical Spine Trauma in a Regional Neurosurgery Unit in a Developing Country: The Example of Senegal
}

\section{Faye Mohameth ${ }^{1,2}$, Barry Louncény Fatoumata ${ }^{2 *}$, Sy El Hadji Cheikh Ndiaye $^{2}$, Djasde Donald ${ }^{1}$, Roger Ilunga Mulumba ${ }^{1}$, Ndongo Mouhamadou Moustapha ${ }^{1}$, Diop Abdoulaye ${ }^{2}$, Cisse Yakhya ${ }^{2}$, Mualaba Célèbre $^{2}$ and BA Momar Code ${ }^{2}$}

${ }^{1}$ Neurosurgery Unit, Regional Hospital Center of Thies, Senegal

${ }^{2}$ Neurosurgery Department, Fann University Hospital, Dakar, Senegal

*Corresponding Author: Barry Louncény Fatoumata, Neurosurgery Department, Fann University Hospital, Dakar, Senegal.
Received: November 14, 2020

Published: January 16, 2021

(C) All rights are reserved by Barry

Louncény Fatoumata., et al.

\begin{abstract}
Introduction: Traumatic injuries of the cervical spine are frequent and are complicated in 15 to $30 \%$ of spinal cord injuries. The prognosis depends on the initial spinal cord injuries and the speed of management. We report our experience in order to evaluate our results and to reveal the difficulties of managing these injuries in our work context.

Materials and methods: over a period of 5 years from January 2015 to December 2019, we retrospectively studied 107 cases of cervical spine trauma in the neurosurgery unit of the regional hospital of Thiès (Senegal).

Results: The mean age was 35.7 years with a sex ratio of 12.3 . The frequency was $67.7 \%$ of all vertebro-medullary traumas. The etiologies were dominated by road accidents (69.2\%) with only $10.28 \%$ of medicalized transport and an average admission time of 50.28 hours. Neurological signs were present in 77 patients (71.9\%) with an ASIA A score in 35.5\% of cases and an ASIA B in 18.7\% of cases. Dislocations were the dominant lesions (60.7\%). Surgery was performed in 75 patients (70\%) with complete improvement of motor deficit in 7 cases. The average delay was 34 months.

Conclusion: This study shows the difficulties of management in our context of patients suffering from cervical spine trauma, due to the failure of the emergency management system and the absence of specialized rehabilitation structures for follow-up care.
\end{abstract}

Keywords: Trauma; Spine; Cervical; Thies

\section{Abbreviations}

RHC: Regional Hospital Center; MRI: Magnetic Resonance Imaging; UCS: Upper Cervical Spine; A-A: Anderson and Alonzo's Classification; ODB: Oblique Down and Back; ODF: Oblique Down and Forward; LCS: Lower Cervical Spine; NCC: Narrow Cervical Canal.

\section{Introduction}

Traumatic lesions of the cervical spine are frequent and potentially serious [1]. They are observed in $2-3 \%$ of polytraumatized patients and up to $45 \%$ of severe head injuries [2]. In Europe, cervical spine trauma accounts for $45 \%$ of vertebro-medullary trauma [3]. They are complicated in 15 to $30 \%$ of cases of spinal cord injury $[2,4]$. The prognosis depends on the initial spinal cord injuries and the speed of treatment [5]. While upper cervical spinal cord injury is often life-threatening, lower cervical spinal cord injury can sometimes result in serious neurological sequelae that require a multidisciplinary medical and paramedical approach to avoid complications. The final outcome is then the result of several factors, ranging from the efficiency of the spine trauma emergency management system to the rehabilitation structures [5]. In our context, this chain of care is deficient at various levels, especially in the areas of collection, transport and follow-up care, including rehabilitation with complications of often lethal decubitus. 
Difficulties in the Management and Prognosis of Cervical Spine Trauma in a Regional Neurosurgery Unit in a Developing Country: The Example of Senegal

We report our experience in order to evaluate our results and to reveal the difficulties encountered in the management of these injuries in our work context.

\section{Material and Methods}

This was a 5-year retrospective study from January 1, 2015 to December 31, 2019, at the neurosurgery unit of the Regional Hospital Center (RHC) of Thiès, covering 107 cases of cervical spine trauma treated in the said unit. The parameters studied were frequency, age, sex, circumstances of the trauma, mode of transport, admission mode, admission delay, ASIA score, associated lesions, paraclinic (standard radiography, CT scan and magnetic resonance imaging), type of treatment, in case of surgical treatment: delay, approach, osteosynthesis material used, length of hospitalization, anatomical reduction, neurological evolution, complications, fusion rate. The data were analyzed using SPSS version 18 software.

\section{Results}

During the study period, 158 cases of spinal trauma were recorded, among them there were 107 cases of cervical spine trauma, a frequency of $67.7 \%$ with 12 cases of upper cervical spine trauma $(11.2 \%)$ and 95 cases of lower cervical spine trauma (88.8\%). The mean age was 35.7 years (extremes: 10 and 65 years) with a clear male predominance, 99 men (92.5\%) and 8 women $(7.5 \%)$, i.e. a sex ratio of 12.3 . The etiologies were variable, dominated by road traffic accidents. Table 1 summarizes the etiologies. Patient transport was non-medicalized in $89.71 \%$ of cases compared to $10.28 \%$ medicalized transport. Patients were transported directly from their accident sites to the emergency room of the Thiès RHC in $28.9 \%$ of cases, while $71.2 \%$ of patients were transferred from another health facility. The average admission time after the trauma was 50.28 hours with extremes of 2 hours and 408 hours (17 days).

\begin{tabular}{|l|c|c|}
\hline Etiologies & Staff & Percentage \\
\hline Road accident & 74 & 69,2 \\
\hline Falls & 28 & 26,2 \\
\hline Others & 5 & 4,7 \\
\hline Total & 107 & 100,0 \\
\hline
\end{tabular}

Table 1: Distribution of patients by etiology.

On admission all patients had a spinal syndrome. Torticollis was observed in 35 patients (32.7\%) and cervico-brachial neuralgia in 3 patients $(2.8 \%)$.

Neurological signs were varied and present in 77 patients (72\%) with ASIA score A or B in 54.2\%, sphincter disorders 29.9\%, priapism 15.5\%, Babinski's sign 79.2\% and respiratory distress with hemodynamic instability in $19.6 \%$.

Associated lesions were noted in 21 cases (19.6\%), they were mainly head injuries.

The radiological assessment included a cervical spine CT scan in all patients, a cervical X-ray in 105 patients and a complementary magnetic resonance imaging (MRI) in 9 patients, which revealed a variety of lesions (Table 2, Figures 1, 2), dominated by dislocations in 45 cases $(42 \%)$.

Treatment was orthopedic in 32 patients (30\%), consisting of a foam cervical collar for 2 weeks in mild sprains and a rigid cervical collar for 2 to 3 months in other lesions. Surgery was performed on 75 patients (70\%). Only 19 patients or $26 \%$ were operated on within one week of admission. Figure 3 summarizes the operating time after admission. Seventy-four patients underwent anterior surgery and one patient underwent posterior surgery, 70 patients underwent an iliac graft arthrodesis with targeted plate osteosynthesis, 4 patients underwent an iliac graft arthrodesis alone without plate and one patient underwent posterior screw fixation. Anatomical reduction was achieved in $99 \%$ of cases (74 patients) with a fusion rate of $89.3 \%$

\begin{tabular}{|l|c|}
\hline Radiological injuries & Staff \\
\hline UCS lesions & 12 \\
\hline Type II A-A (ODB) & 5 \\
Type II A-A (ODF) & 2 \\
Jefferson Fracture & 4 \\
Hangman fracture & 1 \\
LCS injuries & 95 \\
\hline Tear drop & 8 \\
\hline Burst & 2 \\
\hline Fracture and uniarticular dislocation & 6 \\
\hline Mild sprain & 27 \\
\hline Uni-articular dislocation & 1 \\
\hline Herniated disc & 1 \\
\hline Biarticular dislocation & 45 \\
\hline Contusion on NCC & 1 \\
\hline Severe sprain & 4 \\
\hline Total & 107 \\
\hline
\end{tabular}

Table 2: Distribution of patients according to radiological lesions. UCS: Upper Cervical Spine; A-A: Anderson and Alonzo's classification; ODB: Oblique Down and Back; ODF: Oblique Down and Forward; LCS: Lower Cervical Spine; NCC: Narrow Cervical Canal. 


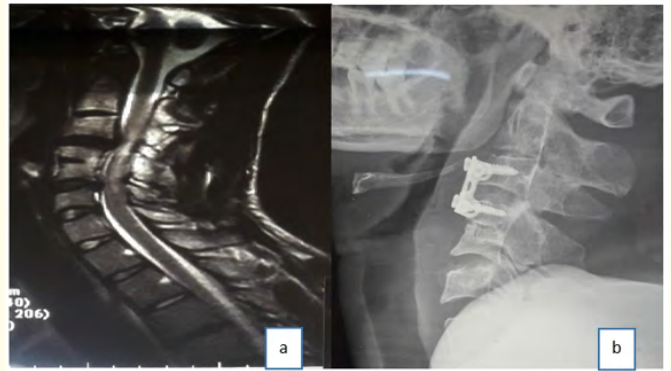

Figure 1

a) Cervical MRI sagittal section T2 sequence: herniated C3-C4 disc.

b) Cervical X-ray profile: C3-C4 interbody graft and screw plate osteosynthesis.

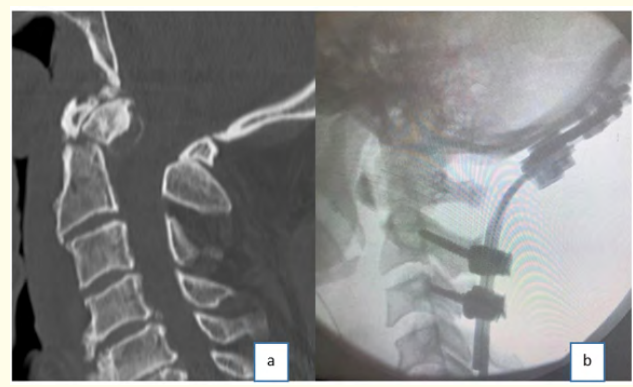

Figure 2

a) Cervical CT scan sagittal section: Anderson and Alonzo's type II odontoid fracture (ODB)

b) Profile occipito-cervical radiograph: occipito-cervical osteosynthesis.

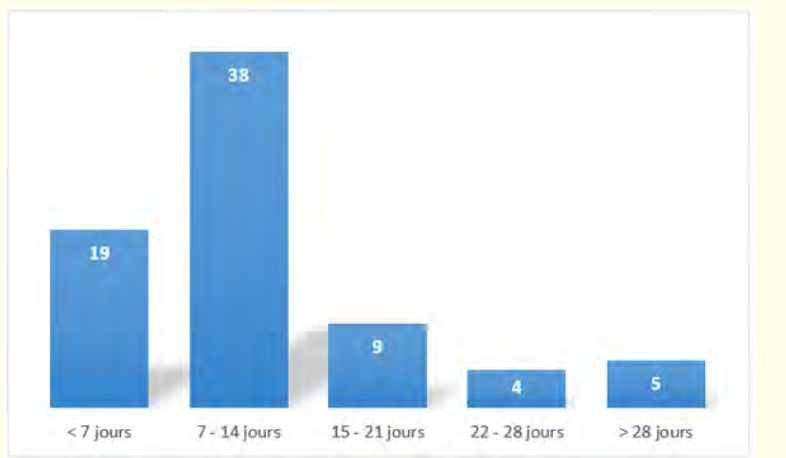

Figure 3: Operating time after admission.
The average length of hospitalization was 17.36 days with extremities ranging from 11 days to 34 days for surgical treatment and 9.5 days with extremities ranging from 2 to 18 days for orthopedic treatment. At discharge, nursing was provided mainly by the patient's family and friends. Rehabilitation was done on an outpatient basis regardless of the patient's neurological condition, usually two to three times a week.

Our average follow-up time was 34 months.

Neurological recovery was complete in 7 cases, partial in 66 cases, stationary in 33 cases and a worsening in one case. Table 3 shows the evolution of the ASIA score at admission and at the end of treatment.

\begin{tabular}{|l|c|c|c|c|}
\hline \multirow{2}{*}{} & \multicolumn{4}{|c|}{ On admission Post-therapy } \\
\cline { 2 - 5 } & Frequency & Percentage & Frequency & Percentage \\
\hline A & 38 & 35,5 & 33 & 30,8 \\
\hline B & 20 & 18,7 & 13 & 12,1 \\
\hline C & 11 & 10,3 & 14 & 13,08 \\
\hline D & 8 & 7,5 & 10 & 9,3 \\
\hline E & 30 & 28 & 37 & 34,5 \\
\hline Total & 107 & 100 & $107^{\mathrm{a}}$ & 100 \\
\hline
\end{tabular}

Table 3: Distribution of Patients by ASIA Score at Admission and Post-Treatment.

${ }^{\text {a }}$ Includes deceased patients.

Complications were varied, and included 1 case of neurological aggravation by graft migration, 2 cases of pseudarthrosis, 2 cases of lower limb thrombophlebitis, 21 cases of pressure ulcers, 7 cases of surgical site infection, 13 cases of urinary tract infection, 2 cases of lung infection, 1 case of esophageal perforation, and 7 cases of death, representing a mortality rate of $6.5 \%$ of cases. We noted 2 cases of intra-hospital death secondary to respiratory distress and 5 cases of death at home following complications of decubitus (table of severe sepsis).

\section{Discussion}

Trauma in general, and spinal trauma in particular, is a public health problem in developing countries because it usually affects the most active population [6,7]. The cervical spine is affected in more than $50 \%$ of cases because it is the most mobile part of the entire spine [8]. Our series involved $67.7 \%$ of cervical segment 
Difficulties in the Management and Prognosis of Cervical Spine Trauma in a Regional Neurosurgery Unit in a Developing Country: The Example of Senegal

trauma over the entire spine trauma during the study period. Traumatic lesions of the cervical spine can affect either the upper cervical spine (C0-C2) or the lower cervical spine (C3-C7) or rarely both at the same time. However, data from the international literature show a predominance of lower cervical spine injuries $[1,9,10]$. In our series, the lower cervical spine was the most affected with $88.8 \%$ compared to $11.2 \%$ for the upper cervical spine. There were no recorded cases of mixed involvement.

The vast majority of cervical rachis trauma affects young adults between 15 and 35 years of age, with an average age of 30 years [11], 35.7 years in our series and 36.1 years in the Dakar series [5]. The male predominance noted in our series is consistent with data from the literature [3-5]. As in our series, by far the most frequent cause reported in the international literature remains road accidents [3-5].

In our work context, the conditions of pick-up and transport are still not well specified at the time of questioning, but in our series, it was non-medicalised transport in $89.71 \%$ of cases compared to $10.28 \%$ medicalised transport. This is due to the lack of personnel trained in the logistics of collecting patients and the low availability of medicalized means of transport. Nearly thirty percent of patients were transported directly from their accident sites to the emergency room of the Thiès Regional Hospital, compared to $71.2 \%$ of patients transferred from another health facility. This transit of patients through several hospitals before being transferred to our center, would explain on the one hand the longtime of admission of patients which was 50.28 hours on average in our series against 10 hours in South Africa [12] and 53 hours in Nigeria [13], probably this admission time is less long in developed countries, it is 1.9 to 6.5 hours in France [14]. This long admission time is also explained by the fact that the population is more isolated than the care structures.

When the traumatized patient was admitted to our hospital structure, the clinical examination began with the search for vital distress (circulatory, respiratory), 19.6\% in our series. Once the vital emergency was eliminated, a detailed and meticulous clinical examination was carried out to guide the diagnosis of the lesion, the radiological assessment and consequently the therapeutic strategy.

In our series, all patients presented with spontaneous or induced cervical pain, $68.8-95 \%$ in series $[15,16]$, 32.7\% with tor- ticollis, $15.9-63 \%$ in series $[15,16]$, and $2.8 \%$ had cervico-brachial neuralgia.

More than half (54.2\%) of our patients had a severe neurological deficit (ASIA A or B) at admission, predictive of a poor functional prognosis $[8,17]$. Computed tomography remains the first-line examination in the exploration of the neurological traumatic spine $[18,19]$, performed in all patients in our series. Magnetic resonance imaging was performed in $8.4 \%$ of cases and only in cases of radio clinical discordance. The initial lesions were dominated by dislocations (42\%) and tear drop (7.5\%), which explains the severe neurological impairment in the majority of our patients.

Due to the predominance of unstable lesions, most patients received surgical treatment (70\%). In some cases, this was mainly palliative to allow nursing. The waiting time for this surgery after the patient was admitted to our unit was also significant, with only 19 patients, or $26 \%$, undergoing surgery within a week of admission. This would be linked to the combination of several factors (lack of financial means, unavailability of osteosynthesis equipment).

Cervical spine surgery can be performed anteriorly, posteriorly, or by double (mixed) approach [20]. However, as in our series, the anterior approach remains the most commonly used, as evidenced by the series of Ordonnez., et al. [21], Kalff., et al. [22] and P.M. Loembe., et al. [23]. It is most often an anterior osteosynthesis almost always involving a plate and a graft, $93.3 \%$ in our series, $62.21 \%$ in the series of P.M. Loembe., et al. [23].

The average length of hospitalization was 17.36 days with extremities ranging from 11 days to 34 days after surgery and an average follow-up of 34 months.

In the absence of hospitalization and rehabilitation facilities specialized in follow-up care for patients with major neurological deficits, at discharge nursing was provided mainly by the patient's family and friends who had no expertise in this field, which increased the risk of complications and compromised neurological recovery. Despite these hazards, the neurological evolution (complete recovery in $6.5 \%$ of cases, partial recovery in $61.6 \%$ of cases, stationary in $30.8 \%$ of cases and worsening in $0.9 \%$ of cases) and mortality (7 cases or $6.5 \%$ ) were acceptable. The majority of patients died at home (5 cases) due to decubitus complications. The main causes of death were infections (urinary, respiratory) and pressure ulcers due to malnutrition.

Citation: Barry Louncény Fatoumata., et al. "Difficulties in the Management and Prognosis of Cervical Spine Trauma in a Regional Neurosurgery Unit in a Developing Country: The Example of Senegal". Acta Scientific Orthopaedics 4.3(2021): 15-20. 
Difficulties in the Management and Prognosis of Cervical Spine Trauma in a Regional Neurosurgery Unit in a Developing Country: The Example of Senegal

\section{Conclusion}

This study shows the difficulties of managing in our context patients suffering from cervical spine trauma, illustrated by dysfunctions ranging from the failure of the emergency management system to the absence of rehabilitation structures specialized in follow-up care, transplanted from the low socio-economic level of most patients and the low availability of osteosynthesis materials. It is therefore important to develop a policy for the management of these patients based on the establishment of an efficient emergency system and the creation of specialized functional rehabilitation centers to receive patients with severe neurological deficits and especially the strengthening of preventive measures, especially for traffic accidents.

\section{Conflict of Interest}

The authors declare that there are no financial conflicts or conflicts of interest.

\section{Bibliography}

1. EL Glaude., et al. "Traumatismes du rachis cervical". Feuillets de Radiologie 46 (2006): 5-37.

2. Gerbeaux P and Portier F. "Stratégies d'imagerie des traumatismes du rachis cervical”. Presse Med 32 (2003): 1853-1856.

3. Hasler RM., et al. "Epidemiology and predictors of spinal injury in adult major trauma patients : European cohort study". European Spine Journal 20 (2011): 2174-2180.

4. Chirossel JP., et al. "Traumatismes vertébro-médullaires". In: Decq P, Kéravel Y, editors. Neurochirurgie. Paris: Universités francophones éditions (1995): 370-393.

5. E Kpelao., et al. "Problématique de la prise en charge des traumatismes graves du rachis cervical en pays sous-développé”. Neurochirurgie 59 (2013): 111-114.

6. Kawu K., et al. "Outcome of conservative treatment of spinal cord injuries in Lagos, Nigeria”. Nigerian Journal of Orthopaedics and Trauma 9.1 (2010) : 21-23.

7. Frielingsdorf Ka nd Dunn RN. "Cervical sfepine injury outcome-a review of 101 cases treated in a tertiary referral unit". South African Medical Journal 97.2 (2007): 203-207.

8. Edouard A. "Prise en charge d'un blessé adulte présentant un traumatisme vertébromédullaire”. Ann Fr Anesth Réanim 23 (2004): 930-45.
9. Seltzer S and Freyser M. "Prise en charge initiale des traumatismes du rachis cervical Le praticien en anesthésie-réanimation" 6.5 (2002) :334-339.

10. Argenson C., et al. "Classification des lésions traumatiques du rachis cervical inférieur". Rachis cervical traumatique. Cahier d'enseignement de la SOFCOT 76 (2000): 42-62.

11. Bracken MB., et al. "Incidence of acute traumatic hospitalized spinal cord injury in the United States, 1970-1977". American Journal of Epidemiology 113 (1981): 615-622.

12. Dunn RN., et al. "Rugby and cervical spine injuries - has anything changed? A 5-year review in the Western Cape". South African Medical Journal 100.4 (2010): 235-238.

13. Babatunde AS. "Spinal cord injuries in Ilorin, Nigeria". West African Journal of Medicine 21.3 (2002): 230-232.

14. JM Yanguiayan., et al. "Prise en charge actuelle du traumatisé grave en France : premier bilan de l'étude FIRST (french intensive care recorded in severe trauma)". Annuelles françaises de médecine d'urgence 2 (2012): 156-163.

15. Robert 0., et al. "Stratégie diagnostique des lésions traumatiques du rachis cervical". Réanimation 13 (2004): 471-476.

16. Loembe PM., et al. "Les traumatismes du rachis cervical. A propos de 40 observations”. Méd. Afr. Noire 33 (1986): 517-541.

17. Narasinga Rao KVL., et al. "Factors affecting longterm outcome in acute cervical cord injury". Indian Journal of Neurotrauma 7.2 (2010): 149-156.

18. Hadley MN., et al. "Guidelines for the management of acute cervical spine and spinal cord cervical injuries. Radiologic assessment of the cervical spine in symptomatic trauma patients". Neurosurgery 50 (2002): 36-43.

19. Griffen MM., et al. "Radiographic clearance of blunt cervical spine injury: plain radiograph or computed tomography scan?" Journal of Trauma 55 (2003): 222.

20. Emejulu JKC and Ekweogwu OC. "Outcome of spinal cord injuries managed in a centre without modern imaging facilities". West African Journal of Medicine 28.6 (2009): 376-379.

21. Ordonez BJ., et al. "Cervical facet dislocation: Techniques for ventral reduction and stabilization". Journal of Neurosurgery 92 (2000): 18-23.

22. Kalff R., et al. "Operative spondyladesis in injuries of the lower cervical spine”. Neurosurgery Review 16 (1993): 211-220. 
Difficulties in the Management and Prognosis of Cervical Spine Trauma in a Regional Neurosurgery Unit in a Developing Country: The Example of Senegal

23. PM Loembe., et al. "Fractures et luxations du rachis cervical inférieur (C3-C7) attitudes thérapeutiques au Gabon". 45 (1998): 628-632.

\section{Assets from publication with us}

- Prompt Acknowledgement after receiving the article

- Thorough Double blinded peer review

- Rapid Publication

- Issue of Publication Certificate

- High visibility of your Published work

Website: https://www.actascientific.com/

Submit Article: https://www.actascientific.com/submission.php

Email us: editor@actascientific.com

Contact us: +919182824667 